\title{
21
}

\section{Process Assessment Method - an approach for business process development}

Terho Laakso

Helsinki University of Technology

TAI Research Center

PO BOX 9555, FIN-02015 Espoo

Tel: +35894512851 Fax: +35894513665

E-mail: terho.laakso@hut.fi

\begin{abstract}
This paper introduces a method that facilitates the effective implementation of capable business processes. The capability of a business process is defined to be its ability to satisfy customers' expectations by using available resources as efficiently as possible and to be adaptive to changes in external and internal requirements. In the paper it is discussed "how companies could be helped to develop and implement capable business processes".
\end{abstract}

The proposed process assessment method combines hard system analysis techniques with participation of employees. It facilitates skills for productive communication, examines system structure, analyses system interrelationships and allows employees to participate in process redesign and implementation. The method has been developed during the EUREKA TIME GUIDE project (EU 11579). In Finland the project included eight pilot companies where the method has been tested.

\section{Keywords}

Business process assessment, Process modeling, Business process re-engineering, Organizational development 


\section{INTRODUCTION}

Enterprises have become more and more aware of business processes. Business process performance is recognized to be the basis for the overall capability of the company. Clear evidence of this is the massive publicity business process reengineering (BPR) has received in the 90's. The discussion about the BPR has been voluminous in journals and books (Davenport, 1995). One of the big issues in the BPR discussions has been how the company should develop its processes. There has been a distinction between incremental improvements advocated by the TQM school (Harrington 1991,Oakland 1993) and radical process redesigning advocated by BPR school (Hammer and Champy 1993, Davenport 1993). However, the reality is not so black and white as Stoddard and Jarvenpaa (1995) have proved in their case studies. They argue that both radical and incremental approaches are needed in different phases of business process development and process change management.

In this paper process development is seen as a system of nested development cycles. There is a cycle that continuously monitors how outputs of the processes fit the external requirements and adjust themselves to the changes, if they are able to. The main concern of this cycle is "do the processes deliver outputs that are needed at the market place at right time and the right price"? If not, processes should be redesigned, which typically involves heavy investments and high risks. The second cycle concerns "how efficiently resources are used in the process". The cycle is continuously seeking opportunities to improve process efficiency by eliminating non-value adding activities, implementing streamlined process structures, empowering employees and setting measures to monitor change. These activities have lower risks and do not require major investments. However, if the second cycle is well managed it could add up to considerable improvements, which could lead to a new competitive edge in the market place. The process assessment method introduced in this paper is developed to support nested process development cycles.

\section{PROCESS CHANGE MANAGEMENT}

According to Kettinger and Grover (1995) process change management is a strategy-driven organizational initiative to improve and redesign business processes to achieve competitive advantage in performance through changes in the relationships between management, information, technology, organizational structure and people.

A business process in this paper is defined to be: "a structured, measured set of activities and flows that use necessary resources of the organization to provide specified output for a particular customer." 


\subsection{Concept of process management}

One of the main drivers for moving from a functional view to a team based process management is a necessity to bring planning and thinking back together with implementing and doing. To maximize the level of improvement in ownership for making things to happen, the thinking and doing are brought as close as possible to the customers and the people making, serving or supporting the organization's products and/or services (Turner, 1995). In addition, Rummler and Brache (1990) claim that the greatest opportunities for performance improvement often lie in the functional interfaces. These critical interfaces are visible only in the horizontal process view of an organization.

Harrington (1991) gives nine characteristics for a well defined and a well-managed process:

- it has someone who is held accountable for the process;

- the boundaries of the process are defined;

- its interfaces and responsibilities are clearly defined;

- it is documented;

- it has measurement and feedback controls;

- it has customer related measurements and targets;

- its cycle time is known;

- it has formalized change procedures;

- opportunities for improvements are continuously sought.

Following the list of Harrington (1991), seven contentions for process management are given:

1. There should be designated process owner who is responsible and accountable for managing and improving the process.

2. Team work is an important part of the process management and teams are the vehicles to bring together needed resources and skills.

3. The abstract concept of business process should be made tangible by using several modeling techniques. Models are used to visualize the structure and behavior of a business process.

4. Customer needs and requirements must be understood throughout the business process.

5. Performance measures, which are aligned with the process objectives, are important tools to drive process thinking and process improvement.

6. Process based organizations should commit themselves to continuous learning and capability development.

7. There must be harmony between vertical and horizontal dimensions of an organization and they must support each other. 


\subsection{Challenges in process change management}

The shift from the functional to the process based organization is always a difficult task not only because it redistributes resources and power, but also because it brings into question employees' most basic assumptions about the nature of the organization.

Seven empirical studies (Bashein et al. 1994, Hall et al. 1994, Zairi and Sinclair 1995, Grover et al. 1995, Guimare and Bond 1996, Majchrzak and Wang 1996, Childe et al. 1996) have been analyzed by the author in order to identify the main challenges and problems faced during the shift from the functional to the process based organizations. The Burke-Litwin (Burke and Litwin, 1992) model has been used as a framework for the analysis. The model defines twelve variables that need to be considered in the change programs. See Figure 1.

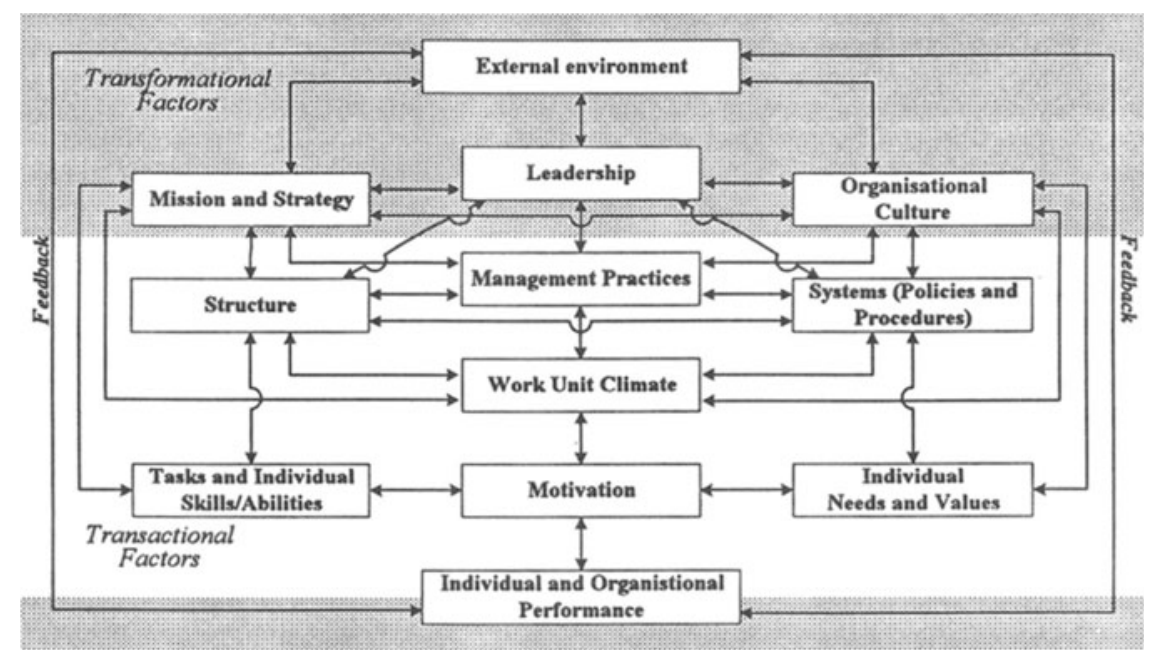

Figure 1 Burke-Litwin model (Burke and Litwin, 1992)

According to the analysis three most difficult areas in process change management are related to:

1. Structure that is the arrangement of functions and people into specific areas and levels of responsibility, decision-making authority, communication, and relationship to assure effective implementation of the organizations mission and strategy. The issues related to this variable according to the studies were such as:

- Project had a wrong sponsor;

- The importance of communication was underestimated;

- Re-engineering team was made-up narrowly;

- Failure to anticipate and plan for the organizational resistance to change;

- Jobs were not structured with overlapping responsibilities and rotation. 
2. Systems that are standardized polices and mechanisms that are designed to facilitate work. They are typically embedded in an organization's reward system, management and information system, quality system and in such control systems as performance appraisal, goal and budget development and human resource allocation. The issues related to this variable according to the studies were such as:

- Needed investments were hard to justify;

- BPR was too disruptive to business operations;

- Rewards were not based on the group performance;

- Lack of tools and skills to promote collaboration horizontally and vertically;

- Performance measures were not aligned according to the processes.

3. Leadership that is executive behavior providing overall direction and serving as role models for all employees about practices and values in the organization. It also encourages others to take needed action to accomplish the strategy. The issues related to this variable according to the studies were such as:

- Failure to build support from line managers;

- Project was run and done by an external "swat" team;

- Lack of a strong director who was willing to make clear demands:

- Senior executives were not fully committed for the BPR project;

- BPR project was subjected to a stand-alone examination.

The review to the empirical studies denoted some requirements that should be taken account in the process assessment method development. Co-operation should be facilitated. Need for change should be understood among employees. The method should enhance reciprocal communication vertically and horizontally. In addition, the method should catalyze thinking on how the measurement system could be aligned according to the change objectives.

\section{CAPABLE BUSINESS PROCESS DEVELOPMENT}

A business process was previously defined to be "a structured, measured set of activities and flows that use necessary resources of the organization to provide specified output for a particular customer". Following this, business process capability is defined to be: "the ability of a process to satisfy customers expectations by using resources as efficiently as possible. In addition, a capable process is adaptive to changes in external and internal requirements."

In this paper the development of a capable business process relies on the taxonomy of systems thinking, organizational learning and proper interventions. This taxonomy is derived from the definition above and the ideas of Checkland (1981), Argyris (1992) and Garvin (1993).

A business process is a combination of technical and social systems with a multiplicity of objectives. In addition, it is in constant change. Checkland (1981) argues that systems thinking is an approach to study and understand such complex dynamic systems. Adaptation i.e. adjustment to environmental conditions needs 
constant reflection of environment and reflection of results of one's actions. This is a basic principle of the organizational learning loop of Argyris (1992). Garvin (1993) has stated that without the implementation of changes only the potential for improvement exists. To enter into an ongoing system in order to help it in change implementation or process adaptation some knowledge of interventions is needed.

Understanding the business process as a dynamic system

According to Senge et al. (1994) a new understanding of the process of change emerges not top-down or bottom-up, but participative at all levels - aligned through common understanding of a system. Senge (1990) adds that systems thinking aims at seeing interrelationships and continuums. It separates detail complexity from dynamic complexity. The detail complexity arises when there are many variables. The dynamic complexity arises when cause and effect are distant in time and space, and when the consequences of interventions over time are hidden and not obvious.

Systems thinking attempts to focus on areas of high leverage. Tackling a difficult problem is often a matter of seeing where the high leverage lies and where a change - with a minimum of effort - would lead to lasting and significant improvements (Senge, 1990).

Systems, hence business processes are dynamic when events occur that change their properties (Smith, 1982). Coyle (1977) argue that the dynamics of a system arise from three sources:

- Shocks imposed by the environment on the business process and/or on the markets i.e. customers and competitors;

- Operating polices within the business process;

- Policies and reactions within the markets.

According to Forrester (1975) three basic types of information are needed for studying dynamic systems: structure, delays in decisions and actions, and policies on managing material flows.

\section{Business process as a learning system}

In the absence of learning, processes simply repeat old practices. Change remains cosmetic, and improvements are either incidental or short-lived. Without implementation of changes in the ways of working only the potential for improvement exists (Garvin, 1993). Capable business processes require a commitment to learning.

According to Garvin (1993) organizational learning can usually be traced through the three overlapping stages. The first step is cognitive. Members of organization are discovering new ideas, expanding their knowledge and beginning to think differently. The second step is behavioral. Employees begin to internalize new insights and alter their behavior. The third step is performance improvement. Changes in behavior lead to measurable improvements in results: improved quality, shorter lead times or increased customer satisfaction, etc. 


\section{Process interventions}

Different interventions have different dynamics. Interventions do different things because they are based on different causal mechanisms. Selection of an intervention type is dependent on the objectives and the target group of the intervention (French and Bell, 1995). However, the basic requirements and the primary tasks for any intervention activities regardless of the substantive issues involved are (Argyris, 1970):

- Generation of valid information that describes the factors and their interrelationships, that create problems for the client system (object of an intervention).

- To help the client system make free but informed and responsible choices. The client should remain responsible for their destiny and maintain their autonomy.

- To build client's internal commitment to the choices.

Intervention should help the client to create ownership and a feeling of responsibility about the selected choice and its implications. In addition, the client system should come to the point where it begins to change its behavior according to choice (Argyris, 1970).

\section{A METHOD FOR BUSINESS PROCESS ASSESSMENT}

The process assessment method (PAM) introduced in this paper combines qualitative and quantitative modeling methods. Qualitative models are graphical presentations of a business process. Quantitative models represent mathematical or logical relationships which are believed govern the behavior of the business process.

The objective of the PAM is to help companies to improve their understanding of business processes. One of the best ways to learn about organizational reality is to model current processes and through this examines an organization's operation and behavior patterns. An understanding of the company's current set of beliefs and values, and the unwritten but underlying business assumptions that are driving operations, is a prerequisite for the process development. Change is not possible without uncovering these assumptions (Laakso et al. 1996).

The process assessment method is a cyclical process and it is conducted by participative cross-functional and cross-hierarchical teams to ensure a broad knowledge sharing about the studied process. See Figure 2. The method consists of several individual interventions. 


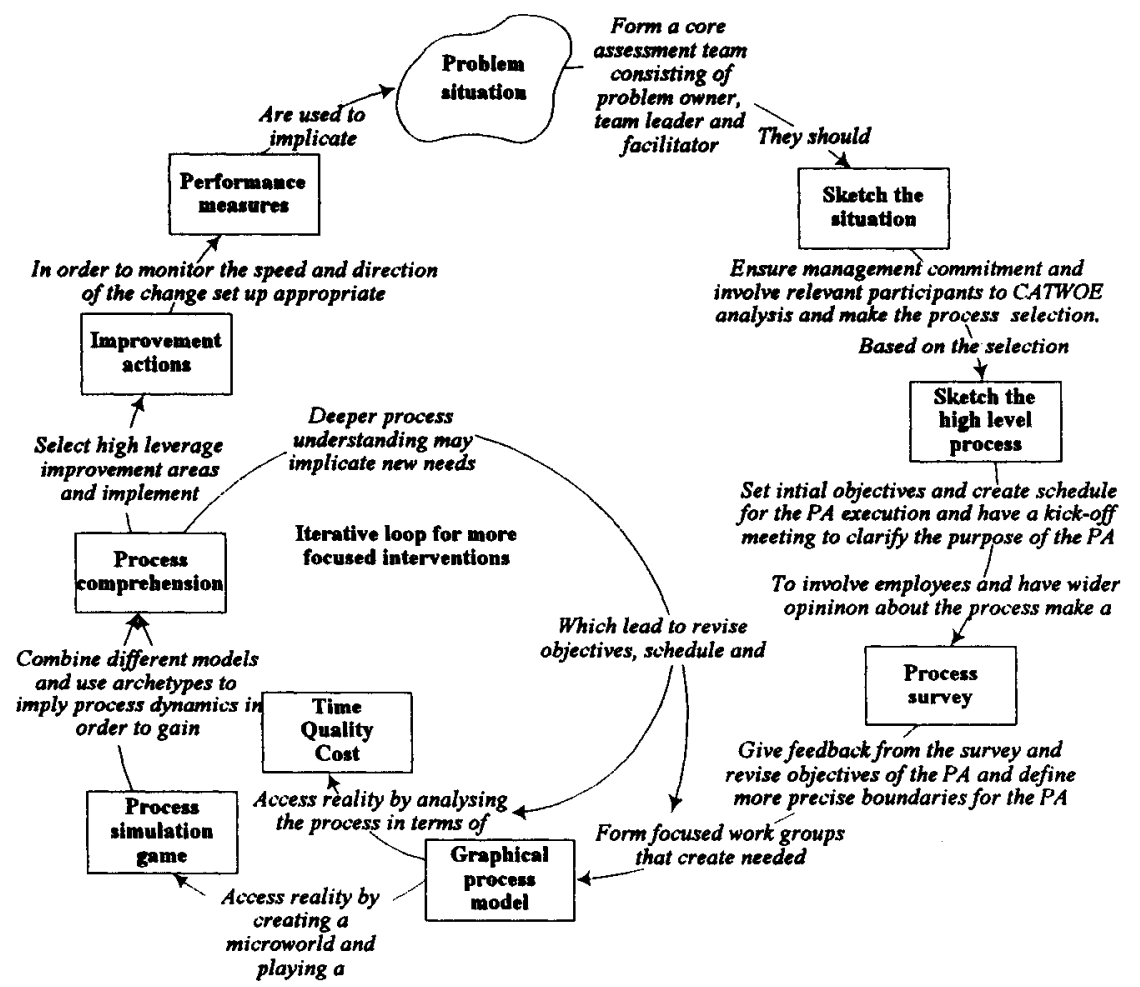

Figure 2 The process assessment method (Laakso, 1997).

French and Bell (1995) have given six guidelines for managing multiple interventions. These guidelines are taken account in the development of PAM. They argue that several interventions should be managed in a way which:

1. maximizes diagnostic data by beginning with the intervention that provides data needed to make subsequent interventions;

2. maximizes effectiveness by sequencing the interventions so that early interventions enhance the effectiveness of subsequent interventions;

3. maximizes efficiency by sequencing the interventions to save resources such as time, people, material and money;

4. maximizes speed by sequencing the interventions in way that objectives of the project are attained in time;

5. maximizes relevance by beginning with intervention that tries to tackle the most immediate problem according to the management;

6. minimizes psychological and organizational strain.

As a result of the process assessment, a company should have a clear picture of what is happening in the business process. This consciousness is needed in process development where actions are taken and implemented based on the process understanding. Without implementation no changes will be realized. However, the 
aim of the PAM is to gain process understanding and to locate high leverage improvement areas that are needed in development of capable business processes. The scope of the PAM is not in the implementation phase. Yet, it provides useful tools for the implementation process.

\section{CONCLUSIONS}

The process assessment method is a tool for evaluating process structure and its performance, which is needed in process development and management. Clarification of a structure is achieved by creating qualitative process models that are graphical presentations of the process. Process performance and behavior are evaluated through qualitative process analysis.

The PAM offers an overall view of the business process - its flows (inputs and outputs), transformation, performance level, goals and the structure of an organization that performs the process. After the process assessment, the organization should have a clear picture what is happening in the business process. This consciousness is prerequisite for sensible process development and management. The actual process development work begins with the selection of the improvement areas that have the highest leverage. The PAM is a tool to identify these areas.

\section{REFERENCES}

Argyris, C. (1970) Intervention Theory and Method: A Behavioral Science View. Addison-Wesley, Publishing Company, Social Science and Administration Series, USA.

Bashein, B. and Markus, M. L. and Riley, P. (1994) Preconditions for BPR Success and How to Prevent Failures. Information Systems Management, Spring, pp. 98-110.

Burke, W. and Litwin (1992) A Casual Model of Organizational Performance and Change. Journal of Management, Vol. 18, No. 5, pp. 523-545.

Checkland, P. (1981) Systems Thinking, Systems Practice. John Wiley \& Sons, UK.

Childe, S and Maull, R. and Mills, B. (1996) UK Experiences in Business Process Re-engineering; A Scoping study for the Innovative Manufacturing Initiative. Research Report for Grant No. GR/K67328, School of Computing, University of Plymouth.

Coyle, R. (1977) Management System Dynamics. John Wiley \& Sons, UK. 
Davenport, T. (1993) Process Innovation: Re-engineering Work trough Information Technology, Harvard Business School Press, Boston, Massachusetts.

Davenport, T. (1995) Business Process Re-engineering: Where It's Been, Where It's Going. In Grover, V and Kettinger, W. (eds.) Business Process Change: Re-engineering Concepts, Methods and Technologies. Harrisburg, PA: Idea Group Publishing.

Forrester, J. (1975) Collected Papers of Jay W. Forrester. Wright-Allen Press Inc., Massachusetts.

French, W. and Bell, C. (1995) Organization Development: Behavioral Science Interventions for Organization Improvement, Fifth Edition, Prentice-Hall Inc., USA.

Garvin, D. (1993) Building Learning Organization. Harvard Business Review, July-August, pp. 78-91.

Grover, V. and Jeong, S. and Kettinger, W. and Teng, J. (1995) The Implementation of Business Process Re-engineering. Journal of Management Information Systems, Vol. 12, No. 1, pp. 109-144.

Guimaraes, T. and Bond, W. (1996) Empirically Assessing the Impact of BPR on Manufacturing Firms, International Journal of Operations \& Production Management, Vol. 16, No. 8, pp. 5-28.

Hall, E. and Rosenthal, J. and Wade, J. (1994) How to Make Re-engineering Really Work. The McKinsey Quarterly, No. 2, pp. 107-128.

Hammer, M. and Champy, J. (1993) Re-engineering the Corporation: A Manifesto for Business Revolution. Harper Collins Publisher Inc., USA.

Harrington, H J. (1991) Business Process Improvement. Quality Press, McGrawHill, Inc. New York.

Kettinger, W. and Grover, V. (1995) Toward a Theory of Business Process Change Management. Journal of Management Information Systems, Vol. 12, No. 1, pp. 9-30.

Laakso, T. (1997) Performance Evaluation and Process Interventions - A Method for Business Process Development. Acta Polytechnica Scandinavica, Mathematics and Computer Series, No. 86, The Finnish Academy of Technology, Espoo, Finland. 
Laakso, T., Kleinhans, S., Smeds, R. and Doumeingts, G. (1996) Embedding the management of evolution into strategic learning. Ninth International Working Seminar on Production Economics, Innsbruck, Austria, February 19-23, 1996, $19 \mathrm{p}$.

Majchrzak, A. and Wang, Q. (1996) Breaking the Functional Mind-Set in Process Organizations. Harvard Business Review, September-October, pp. 93-99.

Oakland, J. (1993) Total Quality Management; The Route to Improving Performance. Second edition, Butterworth-Heinemann Ltd, Oxford, UK.

Rummler, G. and Brache, A. (1990) Improving Performance: How to Manage the White Space on the Organization Chart. Jossey-Bass, San Francisco.

Senge, P. (1990) The Leader's New Work: Building Learning Organizations. Sloan Management Review, Fall, pp. 7-23.

Senge, P. and Roberts, C. and Ross, R. and Smith, B. and Kleiner, A. (1994) The Fifth Discipline Fieldbook. Nicholas Brealey Publishing Ltd, London, UK.

Smith, A. (1982) Management Systems: Analyses and Applications. The Dryden Press, Japan,

Stoddard, D. and Jarvenpaa, S. (1995) Business Process Redesign: Tactics for Managing Radical Change. Journal of Management Information Systems, Vol. 12, No. 1, pp. 81-107.

Turner, R. (1995) Process Management: The Versatile Approach to Achieving Quality in Project Based Organizations. Journal of General Management, Vol. 21, No. 1, Autumn, pp. 47-61.

\section{BIOGRAPHY}

Terho Laakso received his Ph.D. from Helsinki University of Technology (HUT) in 1997. The subject of his thesis was in the area of business process development. After his M.Sc.(Eng.) graduation in 1989 he has worked as a system engineer and quality manager in Schneider Electric Oy for five years. Currently he is a senior researcher at HUT and undertaking research on business process development and change management. 